\title{
Exercise Prescription for Children with Chronic Kidney Disease
}

\author{
Parisa Nejati ${ }^{1}$, Behnam Sobouti ${ }^{2}$ and Hooman Angoorani ${ }^{1,{ }^{*}}$ \\ ${ }^{1}$ Department of Sports and Exercise Medicine, Hazrat Rasool-e-Akram Hospital, Iran University of Medical Sciences, Tehran, Iran \\ ${ }^{2}$ Ali Asghar Children Hospital, Iran University of Medical Sciences, Tehran, Iran \\ "Corresponding author: Associate Professor of Sports Medicine, Department of Sports and Exercise Medicine, Hazrat Rasool-e-Akram Hospital, Iran University of Medical \\ Sciences, Tehran, Iran. Tel: +98-9125272482, Email: angoorani.h@iums.ac.ir
}

Received 2018 July 18; Revised 2018 December 22; Accepted 2019 January 04.

\begin{abstract}
Chronic Kidney Disease in children is one of the most important topics in public health imposing a great burden on the patient's family and the health organizations. Several parameters including cardiovascular impairment, muscle wasting, anemia, and physical inactivity lead to exercise intolerance in these patients. There is a lot of evidence in favor of the positive effect of regular exercise training in improvement of muscle function, exercise capacity and life quality in the subjects with chronic kidney disease (CKD). Understanding the barriers, motivators and benefits of exercise may aid us to design the CKD-specific behavior change programs to improve their physical activity. To achieve the greatest benefit from exercise in children with CKD, exercise should be prescribed individually for them based on disease condition, physiological and psychological parameters and the patient's limitations.
\end{abstract}

Keywords: Chronic Kidney Disease, Endurance Exercise, Resistance Exercise, Dialysis, Kidney Transplant, Exercise Prescription

\section{Context}

Chronic kidney disease (CKD) is one of the most concerning health-related problems in children, imposing a great burden on the patient's family and the health organizations $(1,2)$. It is estimated that the frequency of CKD among Iranian students is $1.3 \%$ and $1.7 \%$ according to the updated Schwartz and the new Schwartz equation, respectively (3). Based on a previous study in Iran (4), the annual incidence of CKD is 16.8 per million among children which is significantly high. Initial reports indicate that children or teenagers who have CKD are less active compared to the recommended level (5). Although the outcome of physical inactivity has not been completely determined yet, sufficient data supports the association between childhood inactivity and lifetime chronic diseases and obesity in general population (6-8). Sedentary lifestyle has been shown to be related to poor outcome in adults with CKD (9) and also unsatisfactory results after kidney transplantation (10) and these findings can be expected to occur also in children with CKD. Therefore, children with CKD should be persuaded to be more physically active.

In this review, we attempted to evaluate the current evidence regarding advantages and also limitations for exercise prescription in children with CKD. We also described the scientific exercise protocols for children with renal problems.

\section{Limitations of Exercise in Children with CKD}

Identifying obstacles and guiding patients to handle ways to overcome these limitations is a common method used in behavioral therapy. Awareness of the barriers and the motivators about exercise may help us to design the CKD-specific behavior change programs to improve their physical activity. Frequently reported barriers for exercise participation in the general population include health related disability, lack of enough time, inappropriate climate, fear of re-injury (11). However, additional limitations (as follows) should be considered in children with CKD.

\subsection{Physiological Parameters}

Reduced renal blood flow (RBF) during exercise which is directly related to the intensity of physical activity (1214) may be considered as an obstacle for exercise prescription in children with CKD. Shifting of blood to the exercising skeletal muscles during the exercise can describe the decline in RBF. During exercise, glomerular filtration rate (GFR) increases initially, followed by a decline with the increasing intensity of exercise (15). Moreover, the levels of intra renal hormones and other modulators change during the exercise which may affect renal tubular function (15). 


\subsection{Exercise Intolerance}

Another concern is exercise intolerance in children with CKD, which may cause some limitations in the way of exercise prescription for these patients. Patients with CKD have a lower maximal oxygen uptake (VO2max), a cardiorespiratory fitness index, when compared to the general population. Due to several factors including anemia, cardiac dysfunction, skeletal muscle weakness and physical inactivity, exercise tolerance is lower in children with CKD and those getting dialysis or kidney transplant (1518). However, several studies showed that regular aerobic training improve cardio-respiratory fitness and VO2max in adults as well as children with CKD (19-22). Cardiac problems such as diastolic dysfunction and coronary artery disease as well as muscle wasting occur in many children with CKD, which certainly may cause exercise intolerance (23, 24). Physical inactivity as an important predisposing factor of exercise intolerance in children with CKD occurs due to fear of sports-related injuries, anemia, vascular catheter, and arteriovenous fistula-related limitation of physical activity as well as hemodialysis (25).

\subsection{Psychosocial Factors}

Certainly psychosocial factors including economic situation, social support and availability of facilities can affect the level of exercise participation among children with CKD. Other potential motivating parameters are related to the parents, the patients' understanding of their illness and restrictions as well as geographic location (26). It seems that, parental education and encouraging them to invest in exercise would help them to overcome the children's physical inactivity successfully. As shown before, providing a tool such as pedometer for evaluating activity and encouraging children to attend group exercise classes can also control the behavioral barriers (27). On the other hand, considering the result of another study (28) which showed that the physical activity level of the patients was not statistically increased by pedometer (48 steps a day), it can be concluded that using a pedometer alone cannot guarantee increased physical activity. Therefore providing situations that make an activity more enjoyable is needed to increase the amount of physical activity in CKD pediatric patients.

\section{Benefits of Exercise for Children with CKD}

Increasing physical activity and fitness improvement have many potential benefits. According to the current recommendations, patients with CKD should be engaged in moderate exercise for 30 minutes for most days of a week (29). Moderate intensity exercise has been shown to have some health benefits generally. Some of the benefits include decreased chance of coronary heart disease and cerebrovascular events, lower risk of obesity, breast and colon cancer and all-cause mortality in the general population (30). Physical inactivity can be considered as an independent risk factor for all-cause mortality in CKD. Regular exercise can be accompanied by psychological and functional improvement and finally quality of life in these patients (30). All-cause mortality and initiation of dialysis was decreased in the chronic kidney patients who received regular supervised aquatic exercise in a 10 year follow up (31).

\subsection{Cardiac Benefits}

VO2max improvement, as an important index of cardiorespiratory fitness, following exercise training has been reported in several studies (19-21). Also, there is some evidence regarding the improvement of oxygen uptake and exercise performance following two sessions per week of exercise training in children and adolescents with CKD (22).

Moreover, the rate of impairment of many healthrelated cardiac parameters including cardiac output, stroke volume, heart rate, blood pressure and peripheral vascular resistance significantly decrease in patients with CKD following regular exercise training (32).

\subsection{Musculoskeletal Benefits}

Due to lack of sufficient physical activity, many patients with CKD suffer from muscle wasting as well as poor muscle control (19). Van Bergen et al. showed that participating in a community-based high intensity exercise program for 12 weeks despite a high missing rate can improve cardiorespiratory fitness and muscle strength among the pediatric patients with end stage renal disease (33). Resistance exercises can increase muscle strength, muscle endurance and tolerance to exercise in CKD. Kouidi et al. demonstrated that 6 months of resistance training improved skeletal muscle function and structure in patients with CKD (34). Also based on muscle biopsy, the cross section of muscle fibers was increased and new muscle fibers were formatted, while the degenerated fibers were regenerated in Kouidi et al.'s study (34). Moreover, according to another study, resistance training improves the capacity of $\mathrm{O}_{2}$ carrying and following that, exercise tolerance in CKD (35).

Renal osteodystrophy and using glucocorticoids before and/or after transplantation may cause low bone mass in CKDs which is considered as a major public health concern (36). Considering that the efficacy and safety of the drugs of osteoporosis have not yet been addressed adequately in pediatric CKD and thus no evidence-based recommendations regarding the optimal type of bisphospho- 
nate, dosage, or duration of therapy are available, therefore it seems that exercise can be a beneficial method for controlling osteoporosis (37). On the other hand, growth failure is a side effect of CKD in children that can be prevented or delayed by regular exercise. The positive effect of exercise on short stature and bone disease is shown in previous studies (38). They found that treadmill exercise improves tibial bone linear growth, as well as growth plate local IGF-I. Exercise combined with GH treatment shows beneficial effects on trabecular bone formation, suggesting the potential benefit of this combination for CKD patients.

\subsection{Anti-Inflammatory Effect}

A high level of inflammation is generally expected in pediatric CKD leading to an increased risk of secondary health complications for them. Lau et al. showed that acute exercise may have an anti-inflammatory effect on children with CKD which can potentially improve their health condition (39).

\subsection{Psychological Effect}

Patients with CKD may suffer from some psychological as well as emotional limitations of daily activities. There is lots of evidence supporting the positive effect of regular exercise on physical or emotional quality of life $(15,39)$. Regular training may improve mood swings such as depression, fear, anxiety and irritability in CKD (40).

\section{Exercise Prescription After Renal Transplantation}

Renal transplantation (RT) is expected to increase life expectancy in the children with CKD. Nevertheless, many children treated by transplantation do not return to optimal health and have a reduced life expectancy. After kidney transplantation, the physical quality of life was decreased but it was not changed psychologically in children (41). It has been shown that thirty years after RT, the physical quality of life was impaired. Their physical disability over time was worrying and influenced their employment status and social functioning (16). Although the number of studies evaluating the efficacy of exercise in RT is limited, it seems that exercise therapy is an effective intervention for declining the physical disability after RT. The RT recipients have a lower level of physiologic parameters during exercise than their peers (17). For example, lower maximal heart rate, maximal heart rate ratio, and $\mathrm{VO} 2$ max and total energy expenditure.

Supervised endurance and strength training can improve muscle strength, aerobic capacity and cardiac output among adult renal transplant recipients (42). Akber et al. found that among children, Six-minute walk distance was improved in the transplant recipients who increased their steps more than 1000 steps a day by wearing a pedometer for 12 weeks compared to those who did not (37 $\mathrm{m}$ vs $11 \mathrm{~m}, \mathrm{P}=0.006$ ). They also noted that physical function was not significantly different among transplant recipients with or without increased step counts (28).

\section{Exercise Prescription for Pediatric Patients on Chronic Hemodialysis}

The exercise capacity (VO2, anaerobic threshold and treadmill time) of pediatric end stage renal disease getting hemodialysis or peritoneal dialysis is poorer than the healthy children $(18,24,43)$.

Six-minute walking test, forced vital capacity, chair standing test for 1 minute and lower extremity strength are decreased in chronic hemodialysis $(\mathrm{CH})$ patients and are correlated to protein- energy wasting and chronic inflammation (42). Exercise interventions during dialysis have shown promising results (43). Intradialytic exercise program is feasible, effective and acceptable for most children on $\mathrm{CH}$. Thirty-minute sessions of cycle ergometer two to three times a week can improve exercise capacity significantly in the $\mathrm{CH}$ patients (44).

It is also proven that twice-weekly moderate intensity exercise during hemodialysis for 3 months improves lower extremity strength and the result of 6-min walk test significantly (22).

\section{Exercise Prescription for Pediatric Patients with Hy- pertension (HTN)}

Renal disease is one of the most common causes of secondary HTN in children (45-48). Childhood HTN and CKD are related pathophysiologically. Certain forms of CKD may cause HTN, and untreated HTN may cause CKD in adults. However, evidence for the latter in pediatric patients is limited. Almost half of the children and adolescents with CKD are known to be hypertensive (49-51). Education is important for managing hypertension and should be taught to the children or their families appropriately. It should include a suitable dose of medication, a proper diet and the effective level of physical activity. A large body of literature demonstrates the protective effect of physical activity in prevention of HTN in adults (52-54). Moreover, most studies confirm the protective effect of exercise in the children with HTN (55).

Regular aerobic exercise reduces BP significantly and restores vascular changes in the hypertensive children (56). 


\section{Exercise Prescription for Pediatric Patients with a Single Kidney}

Most of health care providers are very concerned about exercise or sports recommendation for children with single kidneys. While based on a current systematic review (57), the absolute risks of renal injury are very low for most sports. Scientific data show that the risks of renal injury are 2.6 incidents per million exposures in male soccer players (57). Furthermore, the majority of sports-related renal injuries are insignificant and rarely need nephrectomy. Contact sports seem to be the cause of physical activity-related renal trauma in less than 20 percent of cases (11). Among different kinds of sports, the operation of all-terrain vehicles, cycling, Alpine sports and horseback riding are the most common sources of renal injury. Parental supervision, use of protective equipment, initial renal health, and the individual's age are factors which can modify the risk of renal injury in children with single kidney. Two to six weeks of limited physical activity is often adequate in children with minor renal injuries without fear of long-term side effects (58). However, subcapsular haematomas can cause a renal tissue necrosis and consequently hypertension, proteinuria and renal insufficiency. Parents should know that serious renal injury is more likely caused by motor traffic events than from sports participation. Moreover, physicians should emphasize the importance of regular training for health improvement of the child. However, they must also highlight the need to take all reasonable protections to reduce risk, including the avoidance of high risk sport activities (57).

\section{Principles of Exercise Prescription in Children with Renal Disease}

Children with renal disease should be advocated to do regular aerobic exercise under supervision initially. The components of fitness program do not need to be changed but the intensity and progression of the program alongside the exercise equipment may need to be modified. A full detailed medical examination and exercise response assessment is mandatory before initiating an exercise program. The exercise program should contain three different parts including flexibility, aerobic and strength training. Endurance and strength training should be prescribed according to the physical abilities and the goals. Proper and enough warm-up and cool down should be considered in an exercise session. The progression of the exercise program in terms of intensity and time should be slow. The children with renal disease should be encouraged to do exercise well hydrated.

The exercise prescription for pediatric patients with CKD is very similar to healthy children and adults. The principles of exercise prescription are defined based on frequency, intensity, time and type of exercise (FITT formula). The American College of Sports Medicine guidelines recommend doing aerobic exercises such as jogging, cycling and swimming at least 3 to 5 times per week, at a moderate intensity (58). The moderate intensity is considered as an activity done at $40 \%$ to $59 \%$ of patient's oxygen uptake reserve (VO2 R) or a rate of perceived exertion of 11 - 14 on a scale of 6 - 20 (58). Each exercise session should last about 20 to 60 minutes; however, shorter periods of exercise are allowed in the children with lower level of fitness (15).

Resistance training should be performed with an interval of at least 48 hours between sessions of the same muscle groups and no more than 3 days per week (58). Almost 10 different major muscle groups should be included in each exercise session (58). Either free weights or machines can be used based on individual preference; however the machines are safer for beginners. Overlay, lower repetitions, submaximal weights, exercising through the full range of motion and frequency of two to three times a week are suitable for a resistance exercise in pediatric renal disease. The suitable intensity in resistance exercises is $60 \%-75 \%$ of one repetition maximum (1RM) (58). Mostly, one set of 10 to 15 repetitions of each exercise is chosen for pediatric patients with renal disease especially during the initial weeks. It is believed that a close supervision of training program can significantly decrease the incidence of injury.

Flexibility exercise for all major muscle groups should be done at least 3 days per week with at least 15 seconds stretching for each muscle group.

\section{Conclusions}

Considering the potential benefits of increased physical activity and improved physical fitness in CKD pediatric patients, being active physically is an important goal among them. It is recommended to perform a combined aerobic exercise and progressive-resistance strength training for upper and lower limbs. Most of these children have lower physical activity and lower compliance of exercise. Parents' role in the management of their children's health is prominent. A family-based approach is needed for all kinds of pediatric diseases but their role in the pathologies such as CKD that are substantially influenced by lifestyle behaviors is highlighted. It provides lots of benefits in the CKD population and needs coherent cooperation between child, parents and health caregiver.

According to this review, it is advocated to encourage the children with CKD to be active physically. Consulting with a sports medicine specialist for evaluating the patient and prescribe a specific exercise program can help the 
nephrologist and patient's family.

Considering the high number of benefits related to exercise in CKD patients, the pediatric nephrologists and parents can let them to enjoy different sports or activities.

\section{Footnotes}

Conflict of Interests: No conflict of interests to disclose. Funding/Support: It is not declared by the authors.

\section{References}

1. Varni JW, Limbers CA, Burwinkle TM. Impaired health-related quality of life in children and adolescents with chronic conditions: A comparative analysis of 10 disease clusters and 33 disease categories/severities utilizing the PedsQL 4.0 Generic Core Scales. Health Qual Life Outcomes. 2007;5:43. doi: 10.1186/1477-7525-5-43. [PubMed: 17634123]. [PubMed Central: PMC1964786].

2. Warady BA, Chadha V. Chronic kidney disease in children: The global perspective. Pediatr Nephrol. 2007;22(12):1999-2009. doi: 10.1007/s00467-006-0410-1. [PubMed: 17310363]. [PubMed Central: PMC2064944].

3. Gheissari A, Kelishadi R, Roomizadeh P, Abedini A, HaghjooyJavanmard S, Abtahi SH, et al. Chronic kidney disease stages 3-5 in Iranian children: Need for a school-based screening strategy: The CASPIAN-III study. Int J Prev Med. 2013;4(1):95-101. [PubMed: 23413177]. [PubMed Central: PMC3570918].

4. Gheissari A, Hemmatzadeh S, Merrikhi A, Fadaei Tehrani S, Madihi Y. Chronic kidney disease in children: A report from a tertiary care center over 11 years. J Nephropathol. 2012;1(3):177-82. doi: 10.5812/nephropathol.8119. [PubMed: 24475412]. [PubMed Central: PMC3886143].

5. Akber A, Portale AA, Johansen KL. Pedometer-assessed physical activity in children and young adults with CKD. Clin J Am Soc Nephrol. 2012;7(5):720-6. doi: 10.2215/CJN.06330611. [PubMed: 22422539]. [PubMed Central: PMC3338276].

6. Ruiz JR, Castro-Pinero J, Artero EG, Ortega FB, Sjostrom M, Suni $\mathrm{J}$, et al. Predictive validity of health-related fitness in youth: A systematic review. Br J Sports Med. 2009;43(12):909-23. doi: 10.1136/bjsm.2008.056499. [PubMed: 19158130].

7. Hasselstrom H, Hansen SE, Froberg K, Andersen LB. Physical fitness and physical activity during adolescence as predictors of cardiovascular disease risk in young adulthood. Danish youth and sports study. An eight-year follow-up study. Int J Sports Med. 2002;23 Suppl 1:S27-31. doi: 10.1055/s-2002-28458. [PubMed: 12012259].

8. Srinivasan SR, Bao W, Wattigney WA, Berenson GS. Adolescent overweight is associated with adult overweight and related multiple cardiovascular risk factors: The Bogalusa Heart Study. Metabolism. 1996;45(2):235-40. doi: 10.1016/S0026-0495(96)90060-8. [PubMed: 8596496].

9. Robinson-Cohen C, Katz R, Mozaffarian D, Dalrymple LS, de Boer I, Sarnak M, et al. Physical activity and rapid decline in kidney function among older adults. Arch Intern Med. 2009;169(22):2116-23. doi: 10.1001/archinternmed.2009.438. [PubMed: 20008696]. [PubMed Central: PMC2878734].

10. Rosas SE, Reese PP, Huan Y, Doria C, Cochetti PT, Doyle A. Pretransplant physical activity predicts all-cause mortality in kidney transplant recipients. Am J Nephrol. 2012;35(1):17-23. doi:10.1159/000334732. [PubMed: 22156548]. [PubMed Central: PMC3251242].

11. Clarke AL, Young HM, Hull KL, Hudson N, Burton JO, Smith AC. Motivations and barriers to exercise in chronic kidney disease: A qualitative study. Nephrol Dial Transplant. 2015;30(11):1885-92. doi: 10.1093/ndt/gfv208. [PubMed: 26056174].
12. Drew RC, Muller MD, Blaha CA, Mast JL, Heffernan MJ, Estep LE, et al. Renal vasoconstriction is augmented during exercise in patients with peripheral arterial disease. Physiol Rep. 2013;1(6). e00154. doi:10.1002/phy2.154. [PubMed: 24400156]. [PubMed Central: PMC3871469].

13. Painter P, KrasnoffJB; American College of Sports Medicine. End-stage metabolic disease: Chronic kidney disease and liver failure. In: Durstine JL, Moore GE, Painter P, Roberts S, editors. ACSM's exercise management for persons with chronic diseases and disabilities. 3 rd ed. Champaign: Human Kinetics; 2009. p. 175-81.

14. Muller MD, Drew RC, Cui J, Blaha CA, Mast JL, Sinoway LI. Effect of oxidative stress on sympathetic and renal vascular responses to ischemic exercise. Physiol Rep. 2013;1(3). doi: 10.1002/phy2.47. [PubMed: 24098855]. [PubMed Central: PMC3787721].

15. Master Sankar Raj V, Patel DR, Ramachandran L. Chronic kidney disease and sports participation by children and adolescents. Transl Pediatr. 2017;6(3):207-14. doi: 10.21037/tp.2017.06.03. [PubMed: 28795012]. [PubMed Central: PMC5532201].

16. Tjaden LA, Vogelzang J, Jager KJ, van Stralen KJ, Maurice-Stam H, Grootenhuis MA, et al. Long-term quality of life and social outcome of childhood end-stage renal disease. J Pediatr. 2014;165(2):336-342 e1. doi: 10.1016/j.jpeds.2014.04.013. [PubMed: 24837864].

17. Derakhshan A, Derakhshan D, Amoozgar H, Shakiba MA, Basiratnia $\mathrm{M}$, Fallahzadeh $\mathrm{MH}$. Exercise test in pediatric renal transplant recipients and its relationship with their cardiac function. Pediatr Transplant. 2014;18(3):246-53. doi: 10.1111/petr.12229. [PubMed: 24483258].

18. Pattaragarn A, Warady BA, Sabath RJ. Exercise capacity in pediatric patients with end-stage renal disease. Perit Dial Int. 2004;24(3):274-80. [PubMed: 15185776].

19. Wang XH, Du J, Klein JD, Bailey JL, Mitch WE. Exercise ameliorates chronic kidney disease-induced defects in muscle protein metabolism and progenitor cell function. Kidney Int. 2009;76(7):7519. doi: 10.1038/ki.2009.260. [PubMed: 19641484]. [PubMed Central: PMC3835682]

20. Moinuddin I, Leehey DJ. A comparison of aerobic exercise and resistance training in patients with and without chronic kidney disease. Adv Chronic Kidney Dis. 2008;15(1):83-96. doi: 10.1053/j.ackd.2007.10.004. [PubMed:18155113].

21. Kouidi E, Grekas D, Deligiannis A, Tourkantonis A. Outcomes of long-term exercise training in dialysis patients: Comparison of two training programs. Clin Nephrol. 2004;61 Suppl 1:S31-8. [PubMed: 15233245].

22. Goldstein SL, Montgomery LR. A pilot study of twice-weekly exercise during hemodialysis in children. Pediatr Nephrol. 2009;24(4):833-9. doi: 10.1007/s00467-008-1079-4. [PubMed: 19093138].

23. Petras D, Koutroutsos K, Kordalis A, Tsioufis C, Stefanadis C. The role of sympathetic nervous system in the progression of chronic kidney disease in the era of catheter based sympathetic renal denervation. Curr Clin Pharmacol. 2013;8(3):197-205. doi: 10.2174/15748847113089990047. [PubMed: 23173962].

24. Eijsermans RM, Creemers DG, Helders PJ, Schroder CH. Motor performance, exercise tolerance, and health-related quality of life in children on dialysis. Pediatr Nephrol. 2004;19(11):1262-6. doi: 10.1007/s00467-004-1583-0. [PubMed: 15368119].

25. Watanabe FT, Koch VH, Juliani RC, Cunha MT. Six-minute walk test in children and adolescents with renal diseases: tolerance, reproducibility and comparison with healthy subjects. Clinics (Sao Paulo). 2016;71(1):22-7. doi: 10.6061/clinics/2016(01)05. [PubMed: 26872080]. [PubMed Central: PMC4737086].

26. Clark SL, Denburg MR, Furth SL. Physical activity and screen time in adolescents in the chronic kidney disease in children (CKiD) cohort. Pediatr Nephrol. 2016;31(5):801-8. doi: 10.1007/s00467-015-3287-z. [PubMed: 26684326]. [PubMed Central: PMC4924924].

27. Lubans DR, Morgan PJ, Tudor-Locke C. A systematic review of studies using pedometers to promote physical activity among youth. Prev 
Med. 2009;48(4):307-15. doi: 10.1016/j.ypmed.2009.02.014. [PubMed: 19249328].

28. Akber A, Portale AA, Johansen KL. Use of pedometers to increase physical activity among children and adolescents with chronic kidney disease. Pediatr Nephrol. 2014;29(8):1395-402. doi: 10.1007/s00467-0142787-6. [PubMed: 24648129]. [PubMed Central: PMC4074553].

29. Howden EJ, Coombes JS, Isbel NM. The role of exercise training in the management of chronic kidney disease. Curr Opin Nephrol Hypertens. 2015;24(6):480-7. doi: 10.1097/MNH.0000000000000165. [PubMed: 26447795].

30. Aucella F, Battaglia Y, Bellizzi V, Bolignano D, Capitanini A, Cupisti A. Physical excercise programs in CKD: Lights, shades and perspectives: A position paper of the "physical exercise in CKD study group" of the Italian Society of Nephrology. J Nephrol. 2015;28(2):143-50. doi: 10.1007/s40620-014-0169-6.

31. Pechter U, Raag M, Ots-Rosenberg M. Regular aquatic exercise for chronic kidney disease patients: A 10-year follow-up study. Int J Rehabil Res. 2014;37(3):251-5. doi: 10.1097/MRR.0000000000000063. [PubMed: 24859430].

32. Kosmadakis GC, John SG, Clapp EL, Viana JL, Smith AC, Bishop NC, et al. Benefits of regular walking exercise in advanced pre-dialysis chronic kidney disease. Nephrol Dial Transplant. 2012;27(3):997-1004. doi: 10.1093/ndt/gfr364. [PubMed: 21795756].

33. van Bergen M, Takken T, Engelbert R, Groothoff J, Nauta J, van Hoeck $\mathrm{K}$, et al. Exercise training in pediatric patients with end-stage renal disease. Pediatr Nephrol. 2009;24(3):619-22. doi: 10.1007/s00467-0081015-7. [PubMed: 18839217].

34. Kouidi E, Albani M, Natsis K, Megalopoulos A, Gigis P, Guiba-Tziampiri $\mathrm{O}$, et al. The effects of exercise training on muscle atrophy in haemodialysis patients. Nephrol Dial Transplant. 1998;13(3):685-99. doi: 10.1093/ndt/13.3.685. [PubMed: 9550648].

35. Sietsema KE, Amato A, Adler SG, Brass EP. Exercise capacity as a predictor of survival among ambulatory patients with end-stage renal disease. Kidney Int. 2004;65(2):719-24. doi:10.1111/j.1523-1755.2004.00411.x. [PubMed: 14717947].

36. Sugatani T. Systemic activation of activin a signaling causes chronic kidney disease-mineral bone disorder. Int J Mol Sci. 2018;19(9). doi: 10.3390/ijms19092490. [PubMed: 30142896]. [PubMed Central: PMC6163495].

37. Haffner D, Fischer DC. Can bisphosphonates play a role in the treatment of children with chronic kidney disease? Pediatr Nephrol. 2011;26(12):2111-9. doi: 10.1007/s00467-010-1739-z. [PubMed: 21267600].

38. Troib A, Guterman M, Rabkin R, Landau D, Segev Y. Endurance exercise and growth hormone improve bone formation in young and growth-retarded chronic kidney disease rats. Nephrol Dial Transplant. 2016;31(8):1270-9. doi: 10.1093/ndt/gfv373. [PubMed: 26560811].

39. Lau KK, Obeid J, Breithaupt P, Belostotsky V, Arora S, Nguyen T, et al. Effects of acute exercise on markers of inflammation in pediatric chronic kidney disease: A pilot study. Pediatr Nephrol. 2015;30(4):61521. doi: 10.1007/s00467-014-2971-8. [PubMed: 25301024].

40. Koufaki P, Greenwood SA, Macdougall IC, Mercer TH. Exercise therapy in individuals with chronic kidney disease: A systematic review and synthesis of the research evidence. Annu Rev Nurs Res. 2013;31:235-75. doi: 10.1891/0739-6686.31.235. [PubMed: 24894142]

41. Schulz KH, Thaiss F. [Long-term outcome with end-stage renal disease - survival is not enough: Does dialysis or kidney transplantation matter?]. Bundesgesundheitsblatt Gesundheitsforschung Gesundheitsschutz. 2012;55(4):543-51. German. doi: 10.1007/s00103-012-1450-2. [PubMed: 22441524].

42. Riess KJ, Haykowsky M, Lawrance R, Tomczak CR, Welsh R, Lewanczuk $\mathrm{R}$, et al. Exercise training improves aerobic capacity, muscle strength, and quality of life in renal transplant recipients. Appl Physiol
Nutr Metab. 2014;39(5):566-71. doi: 10.1139/apnm-2013-0449. [PubMed: 24766239].

43. Paglialonga F, Lopopolo A, Scarfia RV, Galli MA, Consolo S, Brivio A, et al. Correlates of exercise capacity in pediatric patients on chronic hemodialysis. J Ren Nutr. 2013;23(5):380-6. doi: 10.1053/j.jrn.2013.04.006. [PubMed: 23800461].

44. Paglialonga F, Lopopolo A, Scarfia RV, Consolo S, Galli MA, Salera S, et al. Intradialytic cycling in children and young adults on chronic hemodialysis. Pediatr Nephrol. 2014;29(3):431-8. doi: 10.1007/s00467013-2675-5. [PubMed: 24253591].

45. Gupta-Malhotra M, Banker A, Shete S, Hashmi SS, Tyson JE, Barratt MS, et al. Essential hypertension vs. secondary hypertension among children. Am J Hypertens. 2015;28(1):73-80. doi: 10.1093/ajh/hpu083. [PubMed: 24842390]. [PubMed Central: PMC4318949].

46. Baracco R, Kapur G, Mattoo T, Jain A, Valentini R, Ahmed M, et al. Prediction of primary vs secondary hypertension in children. JClin Hypertens (Greenwich). 2012;14(5):316-21. doi: 10.1111/j.1751-7176.2012.00603.x. [PubMed: 22533658]

47. Silverstein DM, Champoux E, Aviles DH, Vehaskari VM. Treatment of primary and secondary hypertension in children. Pediatr Nephrol. 2006;21(6):820-7. doi: 10.1007/s00467-006-0087-5. [PubMed 16703375].

48. Flynn J, Zhang Y, Solar-Yohay S, Shi V. Clinical and demographic characteristics of children with hypertension. Hypertension. 2012;60(4):1047-54. doi: 10.1161/HYPERTENSIONAHA.112.197525 [PubMed: 22892814].

49. Flynn JT, Mitsnefes M, Pierce C, Cole SR, Parekh RS, Furth SL, et al. Blood pressure in children with chronic kidney disease: A report from the Chronic Kidney Disease in Children study. Hypertension. 2008;52(4):631-7. doi: 10.1161/HYPERTENSIONAHA.108.110635 [PubMed: 18725579]. [PubMed Central: PMC3136362].

50. Samuels J, Ng D, Flynn JT, Mitsnefes M, Poffenbarger T, Warady $\mathrm{BA}$, et al. Ambulatory blood pressure patterns in children with chronic kidney disease. Hypertension. 2012;60(1):43-50. doi: 10.1161/HYPERTENSIONAHA.111.189266. [PubMed: 22585950]. [PubMed Central: PMC3439139].

51. Shatat IF, Flynn JT. Hypertension in children with chronic kidney disease. Adv Chronic Kidney Dis. 2005;12(4):378-84. doi: 10.1053/j.ackd.2005.07.002. [PubMed:16198277].

52. Brook RD, Appel LJ, Rubenfire M, Ogedegbe G, Bisognano JD, Elliott WJ, et al. Beyond medications and diet: Alternative approaches to lowering blood pressure: A scientific statement from the american heart association. Hypertension. 2013;61(6):1360-83. doi: 10.1161/HYP.ob013e318293645f. [PubMed: 23608661].

53. Chobanian AV, Bakris GL, Black HR, Cushman WC, Green LA, Izzo JJ, et al. Seventh report of the joint National Committee on prevention, detection, evaluation, and treatment of high blood pressure. Hypertension. 2003;42(6):1206-52. doi: 10.1161/01.HYP.0000107251.49515.c2. [PubMed: 14656957].

54. Pescatello LS, Franklin BA, Fagard R, Farquhar WB, Kelley GA, Ray CA, et al. American College of Sports Medicine position stand. Exercise and hypertension. Med Sci Sports Exerc. 2004;36(3):533-53. doi 10.1249/01.MSS.0000115224.88514.3A. [PubMed: 15076798].

55. Alpert BS. Exercise as a therapy to control hypertension in children. Int J Sports Med. 2000;21 Suppl 2:S94-6. discussion S97. doi: 10.1055/s2000-8497. [PubMed: 11142600].

56. Stabouli S, Papakatsika S, Kotsis V. The role of obesity, salt and exercise on blood pressure in children and adolescents. Expert Rev Cardiovasc Ther. 2011;9(6):753-61. doi: 10.1586/erc.11.63. [PubMed: 21714606].

57. Shephard RJ. Sports participation and the solitary kidney, with particular reference to the child athlete. Int J Appl Sport Sci. 2015;27(2):124-36.

58. Riebe D, Ehrman JK, Liguori G. ACSM's guidelines for exercise testing and prescription.10th ed. Philadelphia: Wolters Kluwer; 2017. p. 334-8. 